\title{
Applications of ToF-SIMS in Surface Chemistry Analysis of Lignocellulosic Biomass: A Review
}

\begin{abstract}
Hong Yan Mou, ${ }^{\mathrm{a}, *}$ Shubin $\mathrm{Wu},{ }^{\mathrm{a}}$ and Pedro Fardim ${ }^{\mathrm{b}, *}$
Time-of-flight secondary-ion mass spectrometry (ToF-SIMS) is an advanced surface-sensitive technique that can provide both spectral and imaging information about materials. Recently, ToF-SIMS has been used for advanced studies of lignocellulosic biomass. In the current article, the application of ToF-SIMS to the characterization of the surface chemical composition and distribution of biomass components in lignocelluloses is reviewed. Moreover, extended applications of ToF-SIMS in the study of pretreatments, modification of biomaterials, and enzyme activity of lignocellulosic materials are presented and discussed. Sample preparation prior to ToF-SIMS analysis and subsequent interpretation of results is a critical factor in ensuring reliable results. The focus of this review is to give a comprehensive understanding of and offer new hints about the effects of processing conditions on the surface chemistry of lignocellulosic biomass.
\end{abstract}

Keywords: Lignocellulosic biomass; Biomaterials; Pretreatment; ToF-SIMS; Surface chemistry

Contact information: a: State Key Laboratory of Pulp and Papermaking, South China University of

Technology, Guangzhou, China; b: Laboratory of Fiber and Cellulose Technology, Abo Akademi

University, Turku/Åbo, Finland andDepartment of Chemical Engineering, KU Leuven, Leuven, Belgium;

*Corresponding author:fehymou@scut.edu.cn; pfardim@abo.fi

\section{INTRODUCTION}

Time-of-flight secondary-ion mass spectrometry (ToF-SIMS) is an important surface-sensitive analysis technique. The chemical composition, orientation, and spatial distribution of materials can be investigated by ToF-SIMS spectral analysis and imaging. It has predominantly been used for the surface analysis of inorganic materials and is also applicable to organic materials. Furthermore, the ToF-SIMS ion microscope can generate specific molecular information without the incorporation of dye, isotopes, or labels. It has been used in the study of biomaterials (Belu et al. 2003) and in the characterization of pharmaceuticals (Barnes et al. 2011).

In recent decades, because of the depletion of fossil fuels and concerns over environmental problems, a wide variety of studies of biofuels and biomaterials have been carried out, including the conversion of lignocellulosic biomass to other forms, to supplement or replace the current high utilization of fossil fuels. Lignocellulosic biomass (e.g., woody and non-woody biomass) is composed of lignin, cellulose, hemicelluloses, extractives, and a few inorganic compounds. The chemical properties and physical structure of lignocellulosic biomass are variable, depending on the type of species. These native structural features of biomass can subsequently impact the utilization process, leading to a sophisticated understanding of the chemical reaction and mechanism. Hence, analytical methods play an important role in determining and understanding the changes that occur in biomass during biological and chemical treatment processes. By detecting secondary ion emission from the sample surface, ToF-SIMS can determine the chemical 
reaction and compositions that would assist in optimizing and improving the process design of biomass utilization. For the proper application of ToF-SIMS in biomass studies, the working principles of ToF-SIMS should first be comprehensively understood.

\section{Basic Measurement Principle of ToF-SIMS}

The ToF-SIMS instrument generally consists of four parts: a primary ion source, mass spectrometer, ion reflectance system, and detector. The working mechanism of ToF-SIMS is simple, as can be seen in Fig. 1. First, the sample is bombarded by a pulsed primary ion gun (1 to $25 \mathrm{keV})$, usually a gallium ion $\left(\mathrm{Ga}^{+}\right)$or cesium ion $\left(\mathrm{Cs}^{+}\right)$source. By determining the time that the secondary ions are released from the sample surface and then the flight-times in travelling to the mass spectrometer, chemical information about the sample can be achieved. The results obtained from ToF-SIMS measurements consist of surface spectroscopy, 2D and 3D surface imaging, and also in-depth ion profiling.

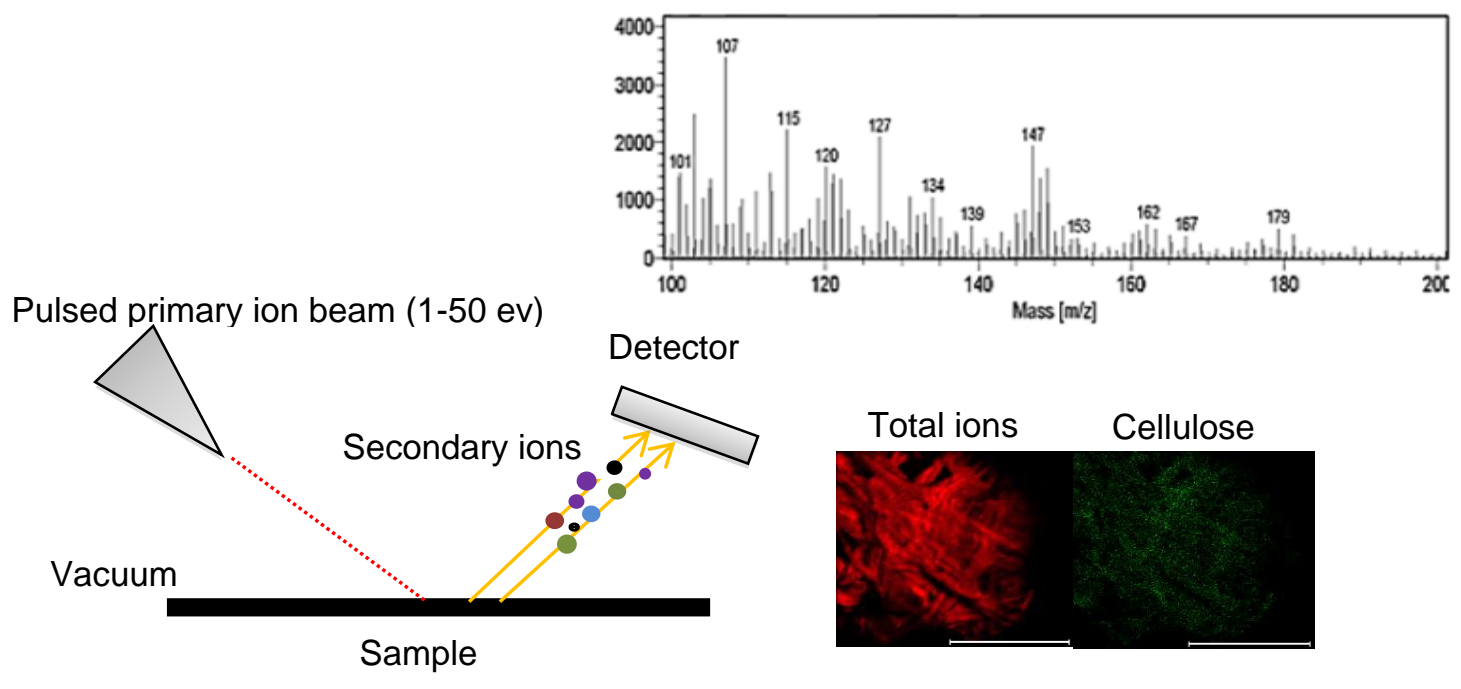

Fig. 1. The principle of ToF-SIMS (spectrum and images measured from Eucalyptus refining pulp)

The total ion mass spectra of positively or negatively charged ions will reflect the chemical composition of the analyzed surface, and the total ion image acquired represents the topography of the material surface. The specific ion image can be achieved by mapping the ion of interest within the total ion spectra. Normally, the analysis depth of ToF-SIMS is approximately 1 to $2 \mathrm{~nm}$. The use of ToF-SIMS usually permits ion imaging of areas as large as $500 \mu \mathrm{m}^{2}$ (Magnusson 2008). Further, the measurement is carried out under high-vacuum conditions. Usually, no pretreatment of the sample is needed for the analysis. The only requirement is that the sample must withstand the highvacuum conditions. The surface of real lignocellulosic biomass consists of many different compounds, all of which have their characteristic peaks and fragmentation patterns, thus generating their own representative spectra. The resulting ToF-SIMS spectra are therefore the sum of all of these individual spectra. This creates a challenge for ToFSIMS spectral analysis and includes sensitivity loss in the high mass range. To simplify interpretation of the final results, surface contamination must be avoided as much as possible during sample preparation. 
Lignocellulosic biomass is heterogeneous in nature. Its composition, containing cellulose, hemicelluloses, lignin, and inorganic substances, is variably distributed in fiber cell walls. The application of ToF-SIMS to biomass analysis has been introduced recently to the study of wood compounds (Tokareva et al. 2010). ToF-SIMS analysis was also used for detecting the surface chemical information of pulp and paper (Fardim and Durán 2000, 2003, 2005; Koljonen et al. 2004; Fardim et al. 2005; Orblin and Fardim 2010). However, ToF-SIMS spectra cannot provide quantitative information about the surface chemical composition. A semi-quantitative method has been presented in the literature to evaluate the surface chemistry of wood and pulp components by comparing the peak ratio of each specific component. In this method, the peaks of specific component fragments identified in the positive spectrum are normalized to the total intensity of secondary ions (Kleen 2000; Kangas and Kleen 2004; Kangas et al. 2007; Mou et al. 2013a, b). By comparing the peak ratio of target fragments, the change of surface chemical composition could be discovered (Mou et al. 2014). In the case of biomass-based biomaterials, ToFSIMS could detect the reaction at the fiber surface by assigning the peak of a specific chemical group in the spectrum. For example, in a study of esterified fibers with fatty acids, ToF-SIMS could observe the occurrence of the esterification reaction because of the dominance of secondary ions of the general type $\mathrm{CH}_{3}\left(\mathrm{CH}_{2}\right)_{n} \mathrm{CO}^{+}$that originated from cleavage of the ester group, which appears at a specific position in the resulting mass spectrum (Freire et al. 2006).

Moreover, using a labeling method with methylene blue, the anionic groups in wood can also be measured by ToF-SIMS (Tokareva et al. 2010). For the study of target chemical groups, ToF-SIMS can directly map the distribution of specific component fragments from both spatial and lateral aspects of the biomass substrate (Zhou et al. 2011; Saito et al. 2012). A more detailed review of the contribution of ToF-SIMS on the surface chemistry analysis of lignocellulosic biomass is presented below.

\section{Characterization of the Surface Chemistry of Lignocellulosic Biomass}

Lignocellulosic biomass was sustainable feedstock for the production of biofuels and biochemicals. It mainly includes natural plants such as trees, grass, and agriculture residues, etc. The differences in various chemical components in biomass are dependent on the species. In the literature, spectroscopic techniques such as UV, Raman, Fourier transform infrared (FTIR), and high-resolution solution-state nuclear magnetic resonance (SSNMR) spectroscopies have been frequently used to determine the chemical structure of the components in biomass. In comparison with these techniques, the advantage of ToF-SIMS is that it can provide both the chemical specificities and the spatial resolution of the distribution of components in lignocellulosic biomass. ToF-SIMS was first applied to detect the surface chemical composition of wood tissue by Fukushima et al. (2001). Through the characteristic secondary ions emitted from the wood surface, the lignin, carbohydrates, extractives, and inorganic ions can be identified, and the distribution of these compounds in tissues and cell walls can be determined (Tokareva 2007; Saito et al. 2008, 2014).

Kleen (2000) demonstrated that ToF-SIMS is capable of providing interpretable and useful information about lignin structures. In that study, the basic lignin units in softwood and hardwood species were identified by ToF-SIMS. Within the mass spectrum, guaiacyl $(\mathrm{G})$ lignin units gave characteristic peaks at m/z 137 and 151; syringyl (S) units had peaks at m/z 167 and 181. This finding has been confirmed by Saito et al. (2005). It was also discovered that most of the main interunit linkages, except the 5-5, 
linkage, can contribute to the characteristic guaiacyl ion peaks located at m/z 137 and 151 (Saito et al. 2005). Additionally, ToF-SIMS is reliable for evaluating the ratio of syringyl/guaiacyl (S/G ratio) units of lignin in wood, and even for determining the $S / G$ ratio at a particular position in a wood sample. Hence, the analysis is easier and faster than Py-GC-MS and NMR (Saito et al. 2005) techniques. ToF-SIMS imaging can also further illuminate the distribution of various units in the wood cell wall (Fukushima et al. 2001).

A ToF-SIMS TRIFT II spectrometer was used to determine the surface chemical component of sugar cane bagasse. The instrument was equipped with a primary ion beam of $69 \mathrm{Ga}^{+}$liquid metal ion source and an electron flood gun for charge compensation. Positive secondary ions were detected using $25 \mathrm{kV}$ acceleration voltage in $8 \mathrm{~min}$. The positive ToF-SIMS spectrum of sugarcane bagasse is shown in Fig. 2. The low mass region (0 to 100) of the spectrum generally consisted of small hydrocarbon fragments in biomass. The peak at the mass-to-charge ratio $(\mathrm{m} / \mathrm{z}) 27$ was particularly strong. It was composed of the overlapping peaks of $\mathrm{Al}(26.98 \mathrm{~m} / \mathrm{z})$ and $\mathrm{C}_{2} \mathrm{H}_{3}(27.02 \mathrm{~m} / \mathrm{z})$. The peak $\mathrm{m} / \mathrm{z}$ 39 relatively strong was assumed to be overlapping of the fragments $\mathrm{C}_{2} \mathrm{HN}$ and $\mathrm{C}_{3} \mathrm{H}_{3}$ (Mou et al. 2014). Chemical fragments originating from cellulose, lignin, or hemicelluloses all can be observed in ToF-SIMS spectra, in the range from zero to 500 $\mathrm{m} / \mathrm{z}$. The lignin component provides the characteristic mass fragments at $\mathrm{m} / \mathrm{z} 107$ and 121 from the p-hydroxyphenyl $(\mathrm{H})$ unit, $m / z, 137$ and 151 from the guaiacyl $(\mathrm{G})$ unit, $m / z, 167$ and 181 from the syringyl (S) unit (Saito et al. 2005), and $m / z 77$ and 91 from general aromatic units (Koljonen et al. 2004; Goarcher et al. 2012). Characteristic carbohydrates peaks can be seen at $m / z$ 115, 133, 127, and 145 (Fardim and Durán 2003).
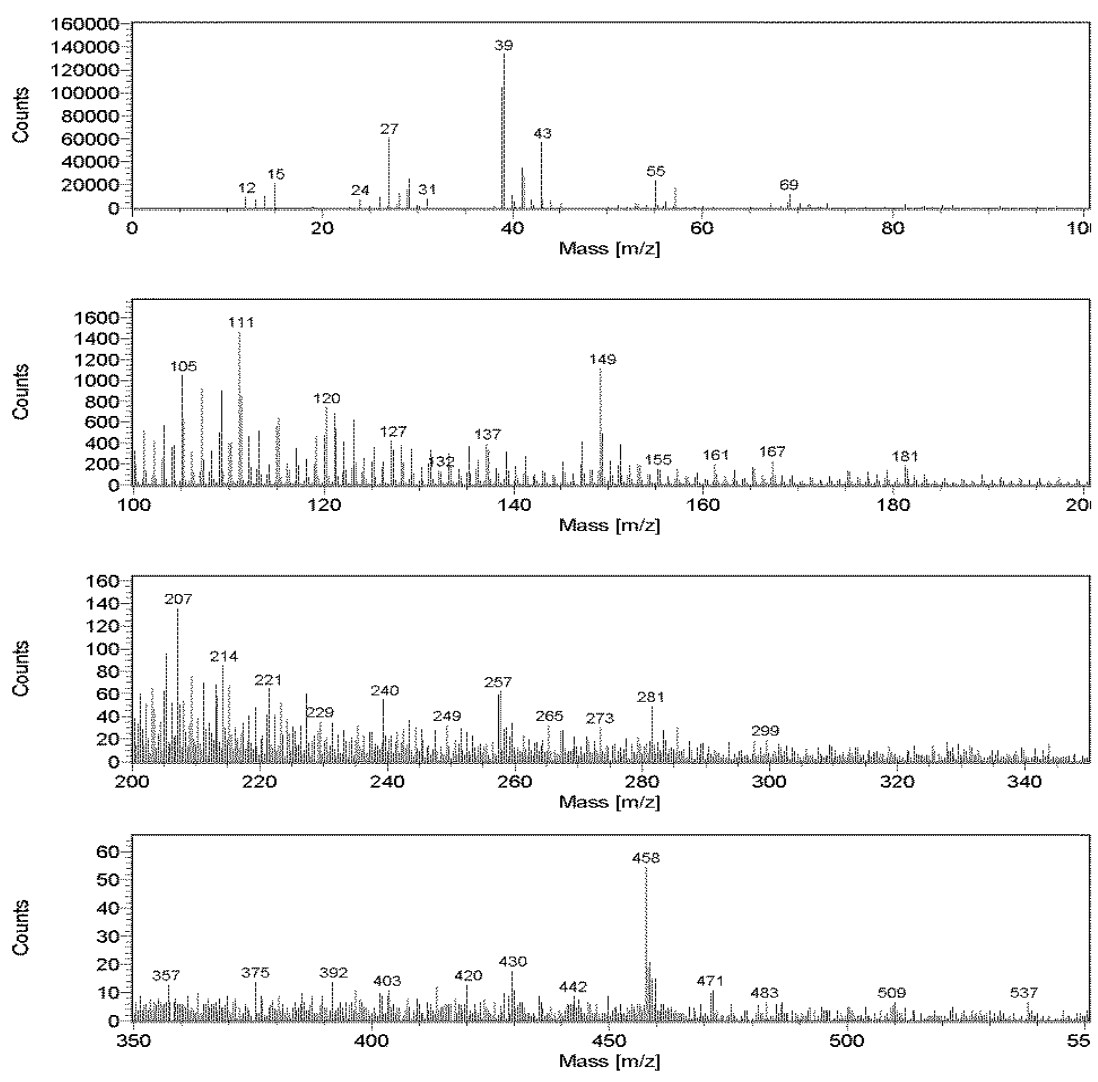

Fig. 2. The positive ion ToF-SIMS spectra of sugar cane bagasse 
ToF-SIMS can provide information about the chemical component distribution on the sample surface simultaneously by mapping the specific peaks from the spectrum. Imai et al. (2005) studied heartwood extractives in Japanese cedar with ToF-SIMS. In his study, ToF-SIMS was used to detect the peaks of extractives in the heartwood and locate them in the heartwood tissue via imaging. Using this technique, it was clarified that more guaiacyl lignin is located in the middle lamella layer and more syringyl lignin is located in the inner cell wall area (Zhou et al. 2011). Thus, directly mapping the chemically specific mass spectrum by ToF-SIMS could elucidate the spatial distribution of chemical components in the investigated region of a sample, as shown in Figs. 3 and 4. Bright pixel represents the detected secondary ions. In the total ion image, all mass fragments detected in the positive secondary ion spectra of sample contribute to the image brightness.

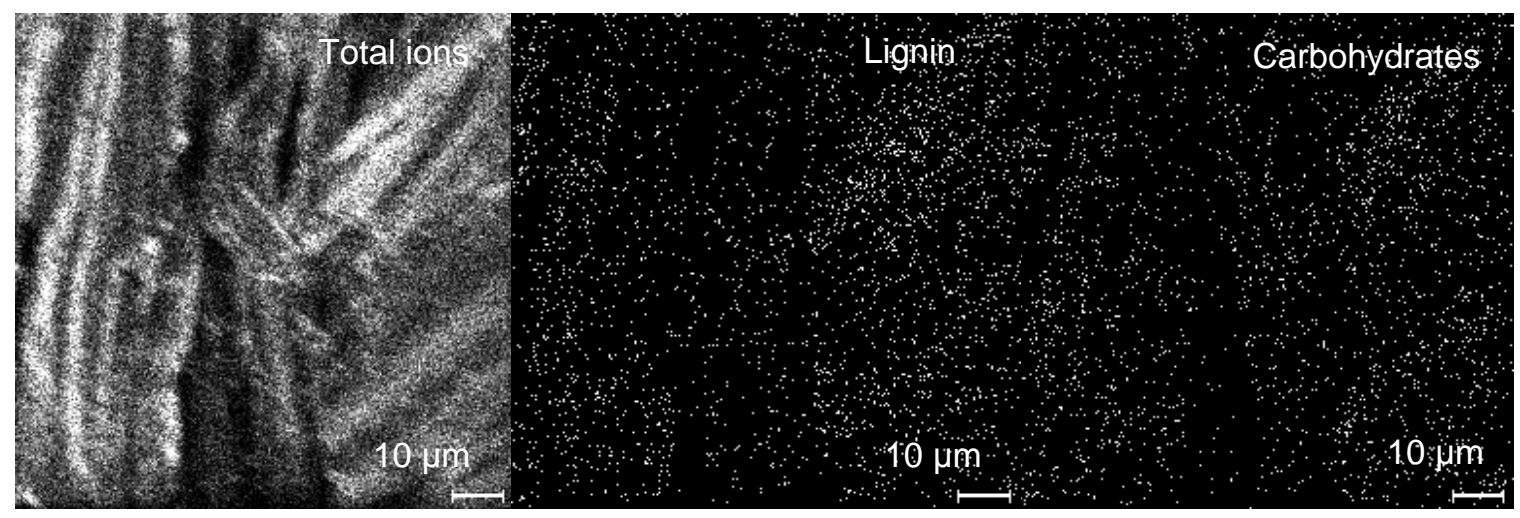

Fig. 3. ToF-SIMS image of surface components distribution on the fiber of sugar cane bagasse

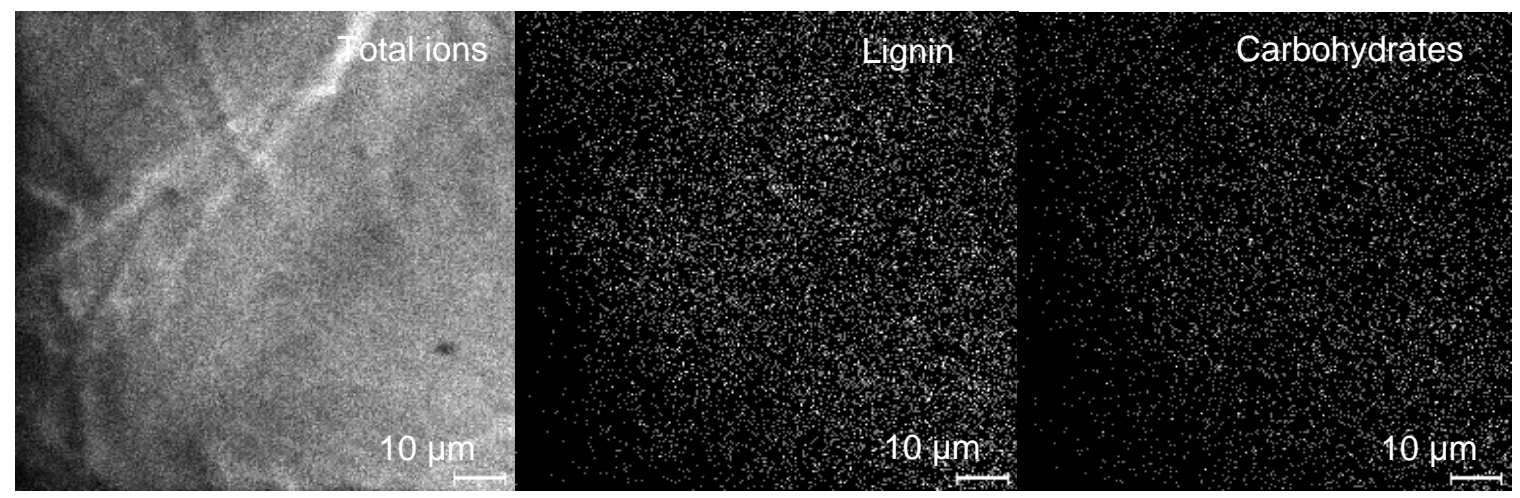

Fig. 4. ToF-SIMS image of surface components distribution on the fiber of common reed

To map the lignin distribution, the peak signals with $m / z 107,121,137,151,167$, and 181 in the spectrum were imaged (Saito et al. 2005), and for mapping carbohydrates, peaks at m/z 115, 133, 127, and 145 were used (Fardim and Durán 2003). Comparing Fig. 3 with Fig. 4, an obvious distinction in chemical composition distribution over the fiber surface between common reed and sugarcane bagasse can be understood. The location of lignin and carbohydrates distributes on fiber surface is distinct. For both samples, the lignin distribution is more intense than carbohydrates on fiber surface.

Understanding the surface chemical properties of each feedstock could help to select and improve a suitable treatment technology for further utilization. 
In the same way, components such as polysaccharides and inorganic components are also able to be determined by ToF-SIMS (Tokareva et al. 2007; Saito et al. 2014). According to a report by Saito et al. (2014), the distribution of aluminum (Al) and other inorganic element levels in the mature xylem of maple can be successfully mapped by ToF-SIMS imaging. It was also found that $\mathrm{Na}, \mathrm{K}, \mathrm{Ca}$, and $\mathrm{Mg}$ ions are almost uniformly distributed in several contiguous growth rings of an air-dried wood sample. In contrast, Al was accumulated heterogeneously and intensely in the cell walls of the secondary xylem (Saito et al. 2014). The intensities of inorganic ions in the biomass sample can be easily monitored based on the ion intensities obtained from the ToF-SIMS spectra. ToFSIMS supplies more information on phytology, which has a great importance for the proper improvement of plant species and their subsequent utilization.

\section{ANALYSIS OF SURFACE CHEMISTRY OF BIOMATERIALS BASED ON LIGNOCELLULOSIC BIOMASS}

\section{Surface Chemical Compositional Analysis of Pulp and Paper}

Pulp and paper is one of the most common applications of lignocellulosic biomass. Several technical processes of production, such as refining, coating, and sizing, are employed to improve and modify fiber and paper quality during papermaking, printing, and finishing operations. The surface chemistry may influence fiber bonding and charge, consumption and adsorption of chemical additives, adhesion and forming of paper, and spreading of printing ink onto paper (Kangas 2007). ToF-SIMS has been successfully applied to the study of lignins, wood, mechanical and chemical pulps, papers, surface treatments, coating, printing, etc. (Kokkonen et al. 2004; Koljonen et al. 2004; Kleen 2005). ToF-SIMS was first introduced into pulp and paper research by Brinen et al. (1991). In that study, the distribution of inorganic species (e.g., $\mathrm{Ca}, \mathrm{Na}$, and $\mathrm{Al}$ ) on paper surfaces was detected by ToF-SIMS. Furthermore, Brinen et al. (1991, 1995) reported that ToF-SIMS could map and provide the imaging for organic additives on the paper surface. In the study of the effect of hydrolyzed alkenyl succinic acid (ASA) on sizing in calcium carbonate-filled paper, Wasser and Brinen (1998) used ToF-SIMS to confirm the chemical changes occurring in hydrolyzed alkenyl succinic anhydride (ASA). The ToF-SIMS technique was also used to directly quantify the alkyl ketene dimer (AKD) size on a paper surface after establishlhing a calibration curve with papers of known AKD loadings (Zimmerman et al. 1995). ToF-SIMS has also been used to solve other paper surface defects, such as fish eyes and brown specks (Brinen and Kulick 1995). Istone (1994) described the use of ToF-SIMS to characterize defects in paper arising because of changes in surface chemistry.

The surface modification of paper by nitrogen plasma treatment was detected by comparison of the systematic changes in the intensities of various mass peaks using ToFSIMS (Deslandes et al. 1998). Other chemical agents, such as cationic starch adsorbed on pulp and sizing agent distributed in paper sheets, were all able to be determined by ToFSIMS (Ozaki and Sawatari 1998; Matsushita et al. 2008). The visualized surface distribution of chemical agents on pulp and paper can be obtained by ToF-SIMS images. The SIMS images have been used to demonstrate clearly the interfaces in an ink film-clay coating-base paper system (Dalton et al. 2002).

For the measurement of a lignocellulosic biomass-related sample, the high-massresolution spectra in positive secondary ion mode over the mass range of 10 to 2,000 Da 
has been suggested using a gallium (Ga) liquid metal ion gun with $15 \mathrm{keV}$ primary ions in a bunched mode. The primary ion current of the instrument was $600 \mathrm{pA}$. At least two areas of $200 \times 200 \mathrm{~mm}^{2}$ on each sample should be analyzed to guarantee the accuracy of the results (Koljonen et al. 2004). Under this detection setting, both inorganic and organic compounds on the outermost surface of the sample can be successfully presented by ToFSIMS spectra and imagery.

For example, in the previous study, the surface distribution of lignin and extractives on pulp after physical treatments such as refining has been interpreted by ToF-SIMS (Fardim and Durán 2003; Mou et al. 2013). In Fig. 5, the distributed location of major chemical components of pulp changed after refining, which can be detected from ToF-SIMS images. Mechanical refining performance could result in an increase in the lignin and extractives on the fiber surface and consequent improvement of chemical agent adsorption on the pulp surface (Fardim and Durán 2003; Mou et al. 2013a, b).
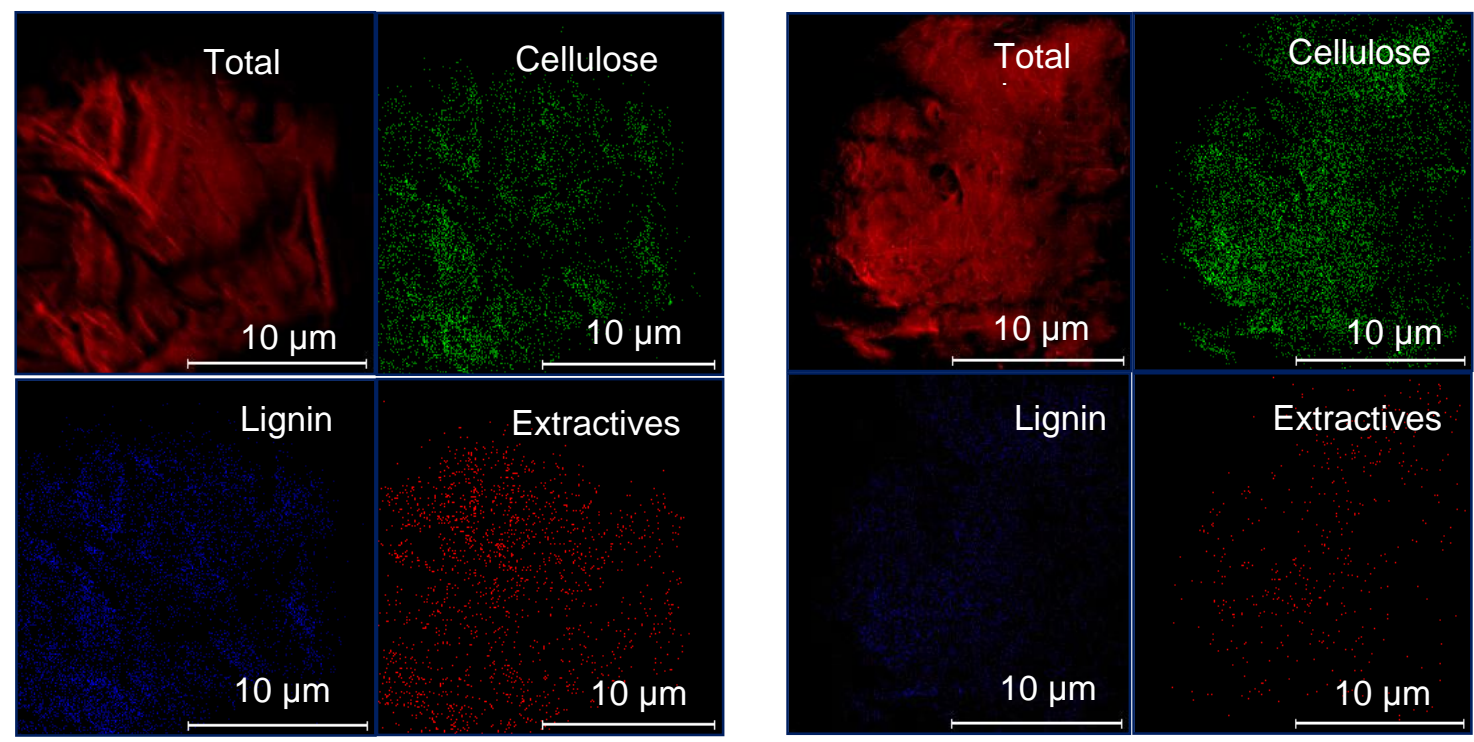

Fig. 5. ToF-SIMS imaging of the distribution of surface components on ECF bleached pine pulp (left) before and (right) after refining

ToF-SIMS has also been used to study the surface components of deinked pulp (DIP), fines of DIP, and the DIP vessel. Chemicals such as calcium salts, optical brightening agents, and retention aids on recycled fiber can also be qualitatively determined by ToF-SIMS spectra and imaging (Fardim and Holmbom 2005; Orblin and Fardim 2010). It was found that the long-chain hydrocarbons dominated the surface of DIP fines, which were assigned at mass units 15, 27, 41, 44, and $69 \mathrm{Da}$ in positive ion spectra (Kangas and Kleen 2004; Fardim and Durán 2005; Fardim and Holmbom 2005). Meanwhile, according to the results provided by ToF-SIMS method, the extractives of DIP pulp and Kraft pulp, primarily fatty acids and their salts, appeared at m/z 200 to 400 in the ToF-SIMS spectrum. Surface lignin in a DIP pulp vessel was found to be primarily syringyl type, according to a demonstration by Orblin et al. (2011). In addition to the chemical composition characterization, ToF-SIMS also has the ability to determine the anionic group distribution on chemical, semi-chemical, and mechanical pulp surfaces (Fardim and Holmbom 2005). By labeling the anionic group with methylene blue and mapping the symbol peaks at $m / z 284\left(\mathrm{C}_{16} \mathrm{H}_{18} \mathrm{~N}_{3} \mathrm{~S}\right)$ and $m / z 268\left(\mathrm{C}_{11} \mathrm{H}_{16} \mathrm{~N}_{3} \mathrm{~S}\right)$ in the 
spectrum, images of surface anionic groups can be obtained. Through this method, Orblin and Fardim (2011) found out that the distribution of anionic groups was more even on kraft fines than on DIP fines (Orblin and Fardim 2011).

Based on the aforementioned studies, ToF-SIMS is able to measure the surface chemical information for various research purposes. However, ToF-SIMS is a qualitative tool with very high sensitivity. Therefore, the extra error and effects from the sample or the instrument should be given close attention while completing the results of any interpretation. According to Fardim's view, roughness of the paper sheet may affect the topography (Fardim and Holmbom 2005). The geometry of the instrument used with a large angle of collection is able to reduce this effect (Prairie 1998). Other artifact sources, such as ion beam shadowing and various anions in the sputter yield with the impact angle, are physical limitations that cannot be avoided. Therefore, several spots are recommended to be analyzed to identify a clear distribution pattern (Fardim and Holmbom 2005).

\section{Study of Modified Cellulose-based Biomaterials}

Biomaterials based on cellulose are very popular currently because cellulose is sustainable and environmentally friendly. Modifying the original cellulose of lignocellulosic biomass could result in substitutes for materials that are refined from fossil resources. For comprehensive investigation of the reaction between cellulose and a modification agent, ToF-SIMS has been introduced for the surface analysis because of the appearance of a new binding moiety in the spectrum (Cunha et al. 2007). In the surface study of trifluoroacetylated cellulosic substrate obtained from bleached kraft pulp of eucalyptus, after excitation with primary ions, the secondary ions of $\left[\mathrm{CF}_{3}\right]^{+}$originating from this reaction were also observed and appeared at $\mathrm{m} / \mathrm{z} 69$ in the spectrum. In addition, the secondary ions of $\left[\mathrm{CF}_{3} \mathrm{CO}\right]^{+}$and $\left[\mathrm{CF}_{3} \mathrm{COO}\right]^{+}$at $\mathrm{m} / z$, 97 and 113 were also observed in ToF-SIMS spectra, which indicated the occurrence of the esterification reaction (Cunha et al. 2007). In that study, it was concluded that the washing and extraction process could remove the residual and unbonded trifluoroacetic ions from the sample, thus preventing extra disturbance on the interpretation of the ToF-SIMS results. In a study of natural fibers as reinforcing agents in composite materials, by characterizing the desired chemical groups at the fiber surface with a ToF-SIMS analysis, the reactions in the modified cellulosic fiber were successfully demonstrated (Baiardo et al. 2002; Zafeiropoulos et al. 2003). In conclusion, ToF-SIMS has proved to be a very suitable technique for chemical surface analysis of polymeric modified biomaterials.

Indeed, the principle of ToF-SIMS with respect to the fiber modification with polymers was to detect the symbolic secondary ion peaks in the spectrum being released from the polymer. For instance, in the study of the modification of kraft pine pulp by cationic xylan polyelectrolytes, the ToF-SIMS analysis could be a good tool to observe the strong interaction between the cationic xylan derivatives and fiber. Two intense signals from ion fragments of xylan polyelectrolytes that are associated with $\left[\mathrm{H}_{2} \mathrm{CN}^{+}\left(\mathrm{CH}_{3}\right)_{2}\right]$ and $\left[\mathrm{HOOC}\left(\mathrm{CH}_{2}\right)_{3} \mathrm{~N}^{+}\left(\mathrm{CH}_{3}\right)_{3}\right]$ ions were observed in the ToF-SIMS spectrum (Vega et al. 2012). Likewise, in another work of Vega et al. (2013), the fiber was modified with functional polysaccharides, including 3-carboxypropyl trimethylammonium chloride ester, carboxymethylxylan, and xylan sulfate, separately. In ToF-SIMS spectra of the fibers treated with functional polysaccharides, the secondary ions of $\left[\mathrm{H}_{2} \mathrm{C}=\mathrm{N}^{+}\left(\mathrm{CH}_{3}\right)_{2}\right]$ released from the functional polysaccharides as a common signal appeared in the spectra of the treated samples. However, no such signals were 
found in the spectra of the untreated fibers. Therefore, this technique could be used to demonstrate the success of the modification on the fiber surfaces. Moreover, the ratio of the counts for the secondary ion peak and the total ion counts can give a semiquantitative estimation of the amounts of functional polysaccharides present on the surface. Furthermore, mapping the symbol fragment to obtain the 2D images could directly provide the extent of the homogeneity of the functional polysaccharides that are distributed on the surface of the fibers (Vega et al. 2012, 2013). In a study of the modification of pine pulp with xylan, ToF-SIMS was used to investigate the xylan distribution on the fiber surface. Using ToF-SIMS imaging to map xylan ions $\left(\mathrm{C}_{5} \mathrm{H}_{7} \mathrm{O}_{3}{ }^{+}\right)$ appearing at $115 \mathrm{Da}$ in the spectra, it was shown expressly that the surface distribution of xylan on the pulp was uniform, which consequently helped to explain the improvement of the mechanical properties of pulp after xylan modification (Grigoray et al. 2014a). In another work of Grigoray et al. (2014b), ToF-SIMS was used to detect a photoactive cationic cellulose derivative on the fiber surface. By running a reference sample, specific signals from secondary ions with $\mathrm{m} / \mathrm{z} 58,159,189$, and 235 were assigned to ions originating from the ion-conducting derivatives. Compared with the modified sample, the effect of modification could be easily determined by ToF-SIMS spectra and 2D-imagery (Grigoray et al. 2014).

The 2D molecular images of ToF-SIMS are frequently used to represent the lateral distribution of characteristic species at a sub-micrometer scale. Some researchers have extended the usefulness of ToF-SIMS to give 3D images by acquiring multiple 2D images in a stack. By stacking the 2D molecular images layer by layer and using reconstruction, a 3D image can be correspondingly observed (Breitenstein et al. 2007). The 3D molecular imaging could present both vertical and lateral distributions of targeted or otherwise interesting parts of a biomass sample.

Jung et al. (2012) applied the use of 3D imagery in a study of component spatial and lateral distributions in biomass. In their work, wood sample surfaces were treated using a $\mathrm{Bi}^{3+}$ primary ion beam. The obtained $3 \mathrm{D}$ molecular ion image displayed the spatial distribution of major cell wall components, from the topmost surface into the subsurface of the tension wood cross section. Cellulose-related ions (green dots) in Fig. 6a were localized in the gelatinous-layer (G-layer) of tension wood, which occurs inside the secondary cell wall layer (S2) and is mostly composed of crystalline cellulose, whereas lignin ions (red dots) were preferentially located at $\mathrm{S}$ and the cell corner (CC). Mass spectral data for the topmost five layers were reconstructed as in Fig. 6b. The cellulose and lignin existing along the line scan in Fig. 6b was semi-quantitatively determined, as shown in Figs. 6c and 6d. According to the 3D images, intensive cellulose-related ions were observed at the G-layer and the signal of lignin was distributed intensively in the $\mathrm{S} 2$ and $\mathrm{CC}$ regions of the cell wall. 

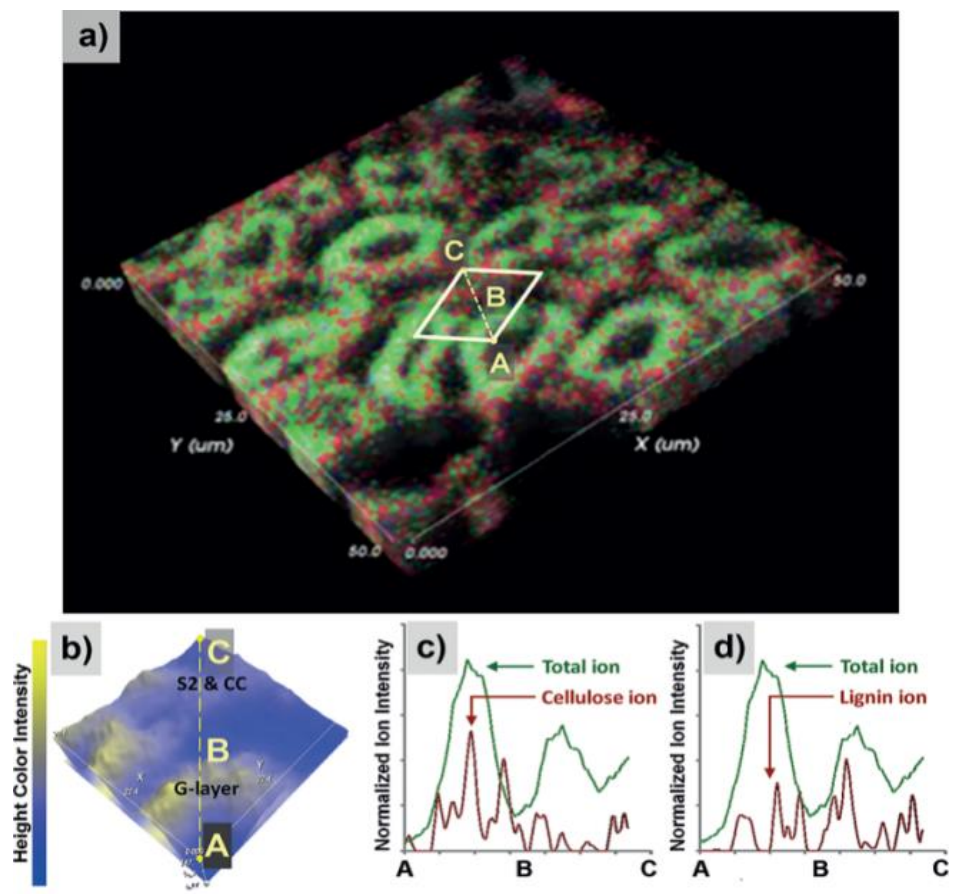

Fig. 6. 3D ToF-SIMS image of tension wood: a) spatial distribution of cellulose (green dots) and lignin (red dots) ions in a 3D volume rendering of a total ion image; b) surface topography of a single cell reconstructed from the topmost five layers; c-d) Semiquantitative lateral distributions of cellulose and lignin across a single cell (Jung et al. 2012; used with permission by Wiley)

Based on this work, 3D-ToF-SIMS could be considered to study the changes in spatial component distribution during the bioconversion of biomass because the interfacial layer between the biomass and cellulolytic enzyme/microbe could significantly affect the hydrolysis efficiency (Chang and Holtzapple 2000). A 3D-image of ToF-SIMS could be used to determine the spatial change in cellulose and lignin in detail during enzymatic hydrolysis. Utilization of ToF-SIMS to explain the mechanism of pretreatment and enzymatic hydrolysis of lignocellulosic biomass is subsequently discussed.

\section{STUDYING THE MECHANISMS UNDERLYING PRETREATMENT AND ENZYMATIC HYDROLYSIS}

The utilization of lignocellulosic biomass as a feedstock to produce biofuel has risen in recent decades. The content and distribution of lignin in biomass is a critical impact factor in its conversion into biofuels (Ragauskas et al. 2006). Cellulase can form an irreversible bond with lignin, leading to the inactivity of the enzyme during hydrolysis (Rahikainen et al. 2011). Therefore, to develop and improve biofuel conversion processes, advanced analytical techniques are needed to study the lignin distribution in wood tissue from the aspects of spatial resolution and chemical specificities. Pretreatment and enzymatic hydrolysis are indispensable procedures in lignocellulosic bioconversion, but their mechanisms are complicated and not completely understood. As a cutting-edge analysis method, ToF-SIMS has been introduced for the study of the pretreatment technology of biomass in the most recent literature. 
ToF-SIMS has been used to monitor the changes in surface lignin and carbohydrates during pretreatment (Jung et al. 2010; Mou et al. 2013c, d, 2014). When applying ToF-SIMS to enzymatic hydrolysis analysis, it was observed that cellulase treatment resulted in the degradation and dissolution of polysaccharides from the wood sample, producing a lignin-enriched surface residue (Goacher et al. 2012). Therefore, the mechanism of polysaccharide hydrolysis after enzymatic hydrolysis can be easily explained by ToF-SIMS. Jung et al. (2010) characterized the surface components of acidpretreated Populus deltoides by ToF-SIMS. The relative content of xylan after diluted acid pretreatment increased by $30 \%$ on the surface of the poplar stem, while bulk carbohydrate analysis showed that the relative concentration of xylose decreased 10-fold in comparison with untreated poplar wood (Jung et al. 2010).

The limitation of ToF-SIMS technology is that it is not able to give absolutely quantitative results. In a study of pretreatment analysis, the changes in composition could be compared by the peak ratio normalized to total ion counts and between substances (e.g., carbohydrates and lignin). This semiquantitative interpretation method has been introduced before in a refining study (Fardim and Durán 2003; Mou et al. 2013c, d). In this way, the lignin degradation and carbohydrates exposed and hydrolyzed after pretreatment and enzymatic hydrolysis can be assessed. For instance, sugarcane bagasse after various pretreatments and enzymatic hydrolysis was studied by ToF-SIMS, with results as shown in Table 1 (Mou et al. 2014). Similar to a previous report on enzyme activity measured by ToF-SIMS, in this study, wood samples were solvent-extracted after fungal degradation prior to ToF-SIMS analysis (Mahajan et al. 2012). The changes in various types of lignin during pretreatment were determined. The difference in delignification efficiency and action between pretreatments was explained through comparison of the peak ratio. The reduction in peak ratio between polysaccharides and lignin can highlight the sugar hydrolysis process during the enzyme treatment. With this study, based on the results from ToF-SIMS, it was shown that removal of surface lignin is more important than the influence of the total amount of residual lignin for enzymatic saccharification.

Table 1. Ratio of the Peak Intensities of the Characteristic Mass Peaks of Carbohydrates and Lignin of Bagasse (B) Samples after Pretreatment and Enzymatic Hydrolysis (E) in ToF-SIMS (Mou et al. 2014)

\begin{tabular}{cccc}
\hline Sample & Carbohydrates/Lignin & Hexose/Total ${ }^{*} 10^{3}$ & Pentose/Total ${ }^{*} 10^{3}$ \\
\hline Bref & $0.67(0.07)$ & $1.1(0.3)$ & $1.7(0.6)$ \\
BN & $1.09(0.51)$ & $2.3(1.4)$ & $3.1(1.8)$ \\
BH & $1.27(0.48)$ & $2.6(1.1)$ & $3.1(1.8)$ \\
Bsxs & $1.82(0.43)$ & $4.8(1.3)$ & $3.7(0.7)$ \\
EBref & $1.02(0.27)$ & $3.1(0.7)$ & $2.7(0.2)$ \\
EBN & $0.36(0.01)$ & $0.7(0.1)$ & $1.2(0.1)$ \\
EBH & $0.47(0.04)$ & $0.6(0.3)$ & $1.0(0.4)$ \\
EBsxs & $0.48(0.12)$ & $0.8(0.3)$ & $2.2(0.9)$ \\
\hline
\end{tabular}

The standard deviation was list in parenthesis. BN: Bagasse pretreated with alkaline; $\mathrm{BH}$ : Bagasse pretreated with alkaline-peroxide; Bsxs: Bagasse after hydrotropic pretreatment 
Furthermore, the images supplied information about the spatial distribution of chemical components in the cross-section of the cell wall. At the same time, the specific component located in the cell wall could be presented in a different color. ToF-SIMS can present the components in vivo. For instance, in Fig. 7, the changes to the surface chemical components of sugarcane bagasse fiber after hydrotropic pretreatment are shown (Mou et al. 2014). The lignin intensity clearly decreased with pretreatment. Comparing the distribution and location of the components on the fiber surface before and after treatment could assist in giving more chemical information for various purposes.

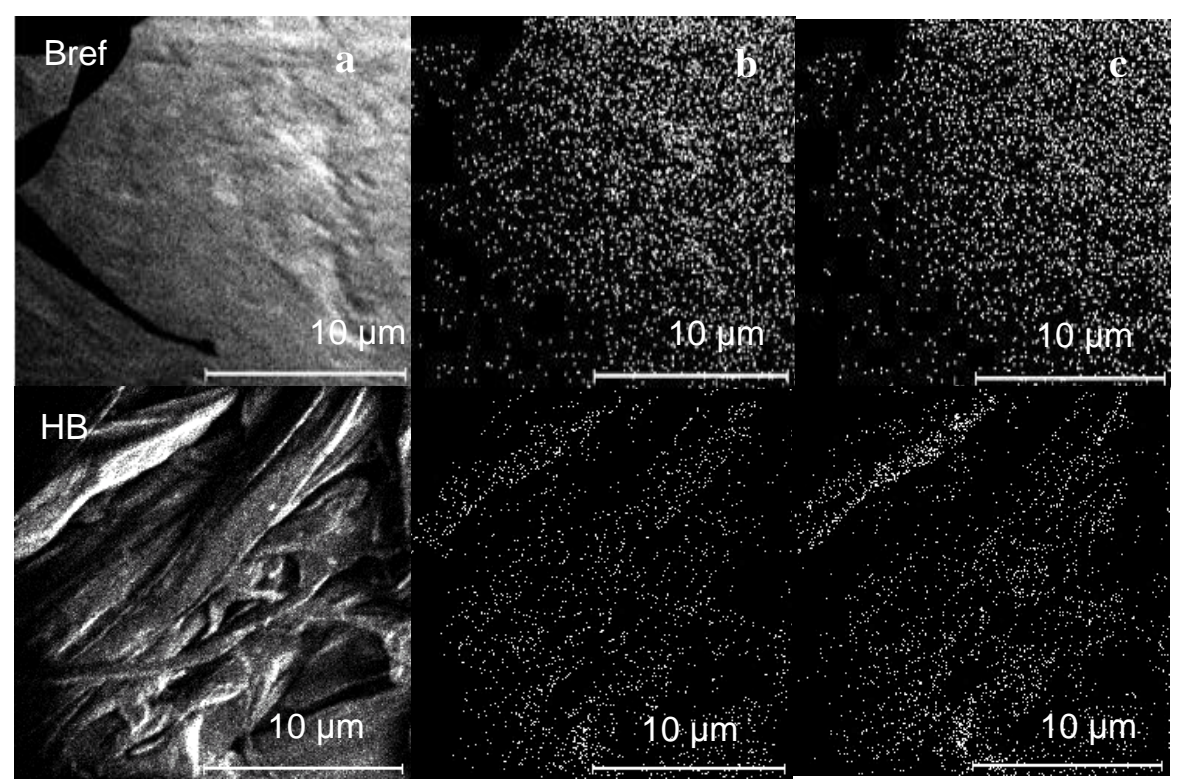

Fig. 7. ToF-SIMS positive ion images of sugarcane bagasse before (Bref) and after hydrotropic pretreatment (HB): ((a) total ions image; (b) lignin units; (c) carbohydrates units)

When applying ToF-SIMS to the detection of an enzyme hydrolysis sample, the buffer used to supply a suitable $\mathrm{pH}$ environment for enzymes has a negative effect on the ToF-SIMS results. The salts peak may cover up other signals coming from the samples, leading to a change in the reliable ion yields of lignocellulose-related ions. Furthermore, when applying ToF-SIMS to study the sample treated with enzyme, some unexpected peaks at 383, 413, 427, 441, and 455 were detected in the spectrum, as shown in Fig. 8. This may have been from enzyme fragments that need to be identified further. 


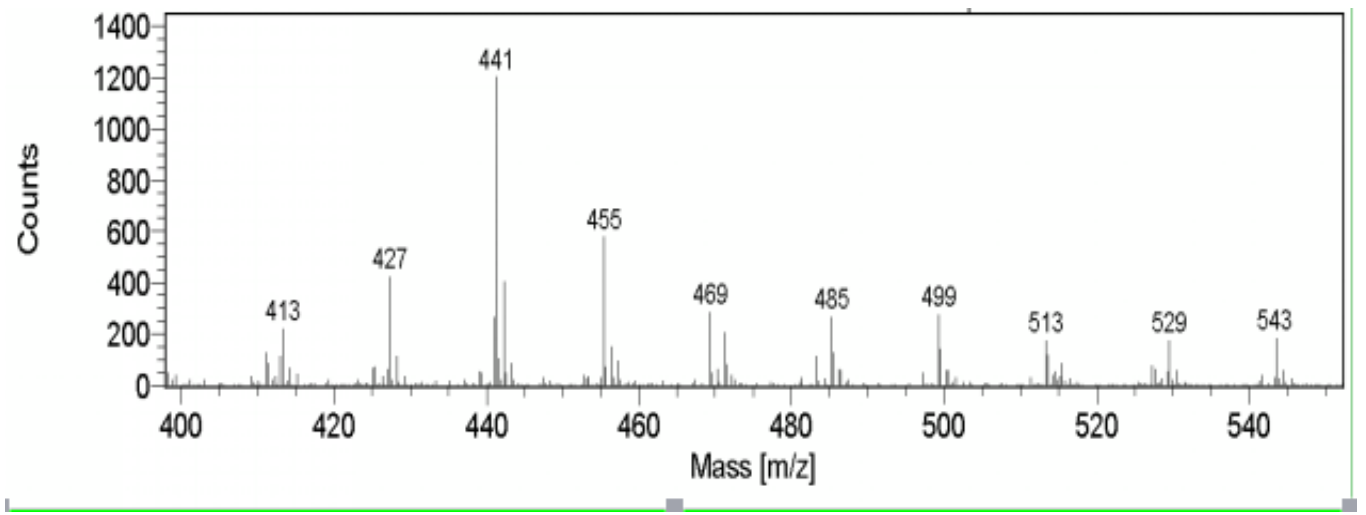

Fig. 8. The positive ion ToF-SIMS spectrum of enzyme-hydrolyzed sugar cane bagasse

Goacher et al. $(2011,2012)$ reported that enzyme activity can be assessed through peak ratios, which are used to measure selective enzymatic wood degradation. In their work, the assessment of enzyme activity by ToF-SIMS was approached through relative quantification of peaks characteristic of lignin and polysaccharides. Within that study, the activity of a cellulase cocktail was clearly evident through the ToF-SIMS spectral analysis. Because of the specificity of enzyme, laccase activity can be detected in the ToF-SIMS spectra with a decrease in $\mathrm{G}$ and $\mathrm{S}$ lignin peaks. Such studies show that applying ToF-SIMS technology has a positive influence on the development of qualitative and high-throughput screening assays for enzyme activity on industrially relevant lignocellulosic substrates.

In another study, a combination of ToF-SIMS and infrared spectroscopy was used to elucidate the mechanism of fungal degradation of two coniferous wood samples (Mahajan et al. 2012). To prevent unexpected interference affecting the ToF-SIMS results, the wood samples were solvent-extracted after fungal degradation and prior to ToF-SIMS analysis. When introducing ToF-SIMS for characterizing lignocelluloseactive enzymes, identifying and avoiding mass interferences from protein adsorption by the enzyme solutions is important (Goacher et al. 2011, 2012). In a subsequent study, it was further shown that solvent-extracting the wood samples could simplify the SIMS spectra (Goacher et al. 2013; Mou et al. 2014), whereby extractives could overlap with lignin and interfere correctly with the study of the peak ratio of lignin in the mass spectra of ToF-SIMS. Because of this, peak ratios based on a selected list, such as the polysaccharide peak fraction and lignin degradation fraction, could lead to erroneous conclusions. Considering the different purposes for research, proper sampling before ToF-SIMS measurement to avoid surface contamination is important for achieving reliable scientific information.

\section{SAMPLE PREPARATION PRIOR TO ANALYSIS}

From the application cases of ToF-SIMS noted above, before running a measurement sample, adequate preparation is a critically important step. Further, ToFSIMS is sensitive to sample preparation and contamination, as these may modify the chemical composition of the surface. Therefore, particular care is necessary during sample preparation prior to ToF-SIMS analysis. According to a report by Tokareva et al. (2007), where Norway spruce was used as the study material, the sectioning process of 
the sample could lead to a high contamination of the wood surfaces by polytetrafluoroethylene (PTFE), which was detected in ToF-SIMS spectra.

A signal from modest phthalate-contamination was detected with $\mathrm{m} / \mathrm{z}$ values of 77, 91, and 149 by Fister et al. (2001). Proper sample drying is also vital for obtaining reliable chemical composition and imaging by ToF-SIMS. When wood tissue sampling is carried out by freeze-drying or air-drying in ambient temperature, the extractive substances will be evenly distributed on the surfaces of the wood section, complicating the ToF-SIMS analysis. Critical point drying and acetone extraction, where each process is followed by drying under nitrogen, is an appropriate sample preparation technique for assessment of the distribution of lignin, carbohydrates, and metal ions in wood tissues. However, the extraction process removes not only extractives but also some amount of metal ions, so caution should be exercised when interpreting the ToF-SIMS images of extracted samples (Tokareva et al. 2007). Solvent-extraction can contribute to reduction of the mass interferences from extractives forming lignin-like ions, which complicate the interpretation of ToF-SIMS data. Because the spectral sensitivity of ToF-SIMS ranges from $\mathrm{ppm}$ to $\mathrm{ppb}$ levels, the potential for surface contamination by plasticizers (e.g., phthalates or poly dimethyl siloxane) should be given attention during sampling (Goacher et al. 2013). Nevertheless, with respect to the elaborations within the literature, ToFSIMS is a promising technique for characterizing lignocellulose-active enzymes. Careful handling of each sample is necessary to avoid surface contamination before the implementation of ToF-SIMS to ensure the accuracy of the results.

\section{CONCLUSIONS}

ToF-SIMS is a versatile functional analysis method that can provide chemical composition, 2D and 3D images, and depth profiling. In addition to the qualitative measurement of lignocellulosic biomass, ToF-SIMS can also supply relative quantification of the chemical compositions by comparing the ratio of peak intensities of the characteristic mass peaks of the desired chemical components. Therefore, the modification and treatment of lignocellulosic biomass can be tested by ToF-SIMS. Although the information observed through ToF-SIMS is sometimes affected by the sample preparation procedure, proper sampling can prevent any disturbances of the ToFSIMS application. In brief, ToF-SIMS is an outstanding tool for further use in lignocellulosic biomass-related research.

\section{ACKNOWLEGEMENTS}

The authors thanks Dr. Shaoxia Wang for reviewing the manuscript. This work is funded by the State Key Laboratory of Pulp and Paper Engineering (201530) and the Fundamental Research Funds for the Central Universities (2015ZM168).

\section{REFERENCES CITED}

Barnes, T. J., Kempson, I. M., and Prestidge, C. A. (2011). "Surface analysis for compositional, chemical and structural imaging in pharmaceutics with mass 
spectrometry: A ToF-SIMS perspective International," Int. J. Pharm. 417(1-2), 6169. DOI: 10.1016/j.ijpharm.2011.01.043

Belu, A. M., Graham, D. J., and Castner, D. G. (2003). "Time-of-flight secondary ion mass spectrometry: Techniques and applications for the characterization of biomaterial surfaces," Biomaterials 24(21), 3635-3653. DOI: 10.1016/S01429612(03)00159-5

Breitenstein, D., Rommel, C. E., Mçllers, R. J., and Hagenhoff, W. B. (2007). "The chemical composition of animal cells and their intracellular compartments reconstructed from 3D mass spectrometry," Angew. Chem. Int. Ed. 46(28), 53325335. DOI: 10.1002/anie.200604468

Brinen, J. S., Greenhouse, and S., Dunlop-Jones, N. (1991). "SIMS (secondary ion mass spectrometry) imaging: A new approach for studying paper surfaces," Nord. Pulp Pap. Res. J. 6(2), 47-52. DOI:10.3183/NPPRJ-1991-06-02-p047-052

Brinen, J. S., and Kulick, R. J. (1995). "SIMS imaging of paper surfaces. Part 4. The detection of desizing agents on hard-to-size paper surfaces," Int. J. Mass Spectrom. IonProc. 143, 177-190. DOI:10.1016/0168-1176(94)04137-V

Chang, V., and Holtzapple, M. (2000). "Fundamental factors affecting biomass enzymatic reactivity," Appl. Biochem. Biotech. 84-86, 5-37. DOI: 10.1007/978-14612-1392-5_1

Cunha, A. G., Freire, C. S. R., Silvestre, A. J. D., Neto, C. P., Gandini, A., Orblin, E., and Fardim, P. (2007). "Characterization and evaluation of the hydrolytic stability of trifluoroacetylated cellulose fibers,” J. Colliod Interf. Sci. 316, 360-366. DOI:10.1016/j.jcis.2007.09.002

Deslandes, Y,. Pleizier, G,. Poiré, E., Sapieha, S., Wertheimer, M. R., and Sacher, E. (1998). "The surface modification of pure cellulose paper induced by low-pressure nitrogen plasma treatment," Plasmas Polym. 3, 61-76. DOI: 10.1023/B:PAPO.0000005939.84830.44

Dalton, J. S., Preston, J. S., Heard, P. J., Allen, G. C., Elton, N. J., and Husband, J. C. (2002). "Investigation into the distribution of ink components throughout printed coated paper Part 2: Utilizing XPS and SIMS," Colloid Surf. A-Physicochem. Eng. Asp. 205(3):199-213. DOI:10.1016/S0927-7757(02)00021-3

Fardim, P., and Durán, N. (2000). "Surface characterization of unbleached eucalyptus kraft pulp using XPS and ToF-SIMS," Proc. $6^{\text {th }}$ European Workshop Lignocellulosics pulp, Bordeaux, September 3-6, p.307.

Fardim, P., and Durán, N. (2003). "Modification of fiber surface during pulping and refining as analyzed by SEM, XPS and ToF-SIMS," Colloid Surf. A-Physicochem. Eng. Asp. 223, 263-276. DOI:10.1016/S0927-7757(03)00149-3

Fardim, P., and Durán, N. (2005). "Influences of surface chemical composition on the mechanical properties of pulp as investigated by SEM, XPS and multivariate data analysis," J. Braz. Chem. Soc. 16(2), 163-170.

Fardim, P., Gustafsson, J., and Schoultz, S. (2005). "Extractives on fiber surfaces investigated by XPS, ToF-SIMS, and AFM," Colloid Surf. A - Physicochem. Eng. Asp. 255, 91-103. DOI:10.1016/j.colsurfa.2004.12.027.

Fardim, P., and Holmbom, B. (2005). "Origin and surface distribution of anionic groups in different papermaking fibres," Colloid Surf. A- Physicochem. Eng. Asp. 252, 237242. DOI:10.1016/j.colsurfa.2004.10.117 
Fardim, P., and Holmbom, B. (2005). "ToF-SIMS imaging: A valuable chemical microscopy technique for paper and paper coatings," Appl. Surf. Sci. 249, 393-407. DOI:10.1016/j.apsusc.2004.12.041

Fister, T., Schuerlein, T., and Lindley, P. (2001) "Contamination monitoring and failure analysis," in: ToF-SIMS Surface Analysis by Mass Spectrometry, Vickerman, J., and Briggs, D. (eds.), IM Publications, UK.

Foston, M., and Ragauskas, A. J. (2010). "Changes in the structure of the cellulose fiber wall during dilute acid pretreatment in Populus studied by ${ }^{1} \mathrm{H}$ and ${ }^{2} \mathrm{H}$ NMR," Energ. Fuel 24, 5677-5685. DOI:10.1021/ef100882t

Freire, C. S. R., Silvestre, A. J. D., Neto, C. P., Gandini, A., Fardim, P., and Holmbom, B. (2006). "Surface characterization by XPS, contact angle measurements and ToFSIMS of cellulose fibers partially esterified with fatty acids," J. Colloid Interf. Sci. 301, 205-209. DOI:10.1016/j.jcis.2006.04.074

Fukushima, K., Yamauchi, K., Saito, K., Yasuda, S., Takahashi, M. and Yoshi, T. (2001). "Analysis of lignin structures by ToF-SIMS," $11^{\text {th }}$ International Symposium on Wood and Pulping Chemistry (ISWPC), Nice, France, 11-14, 327-329.

Goacher, R. E., Edwards, E. A., Mims, C. A., and Master, E. R. (2012). “Application of ToF-SIMS for the detection of enzyme activity on solid wood substrates," Anal. Chem. 84, 4443-4452. DOI: 10.1021/ac3005346

Goacher, R. E., Jeremic, D., and Master, E. R. (2011). "Expanding the library of secondary ions that distinguish lignin and polysaccharides in time-of-flight secondary Ion mass spectrometry analysis of wood," Anal. Chem. 83, 804-812.

DOI: $10.1021 / \mathrm{ac} 1023028$

Goacher, R. E., Tsai, A. Y., and Master, E. R. (2013). "Towards practical time-of-flight secondary ion mass spectrometry lignocellulolytic enzyme assays," Biotechnol. Biofuels. 6, 132. DOI:10.1186/1754-6834-6-132.

Grigoray, O., Järnström, J., Heikkilä, E., Fardim, P., and Heinze, T. (2014a). "Modification of pine pulp during oxygen delignification by xylan self-assembly," Carbohyd. Polym.112:308-15. DOI:10.1016/j.carbpol.2014.05.074

Grigoray, O., Wondraczek, H., Heikkilä, E., Fardim, P., and Heinze, T. (2014b). "Photoresponsive cellulose fibers by surface modification with multifunctional cellulose derivatives," Carbohyd. Polym. 111, 280-287.

DOI:10.1016/j.carbpol.2014.04.089

Imai, T., Tanabe, K., Kato, T., and Fukushima, K. (2005). "Localization of ferruginol, a diterpene phenol, in Cryptomeria japonica heartwood by time-of-flight secondary ion mass spectrometry," Planta 221(4), 549-56. DOI: 10.1007/s00425-004-1476-2

Istone, W. K. (1994). "Static secondary ion mass spectrometry and x-ray photoelectron spectroscopy for the characterization of surface defects in paper products," J. Vac. Sci. Technol. A 12, 2515.

Jung, S., Foston, M., Kalluri, U. C., Tuskan, G. A., and Ragauskas, A. J. (2012). “3D Chemical image using ToF-SIMS revealing the biopolymer component spatial and lateral distributions in biomass," Angew. Chem. Int. Ed. 51, 12005-12008. DOI: 10.1002/ange. 201205243

Jung, S., Foston, M., Sullards, M. C., and Ragauskas, A. J. (2010). "Surface characterization of dilute acid pretreated Populus deltoides by ToF-SIMS," Energ. Fuel 24, 1347-1357. DOI: 10.1021/ef901062p 
Kangas, H., and Kleen, M. (2004). "Surface chemical and morphological properties of mechanical pulp fines," Nord. Pulp Paper Res. J. 19(2), 191-199.

DOI: 10.3183/NPPRJ-2004-19-02-p191-199

Kangas, H., Suurnäkki, A., and Kleen, M. (2007). "Modification of the surface chemistry of TMP with enzymes," Nord. Pulp Paper Res. J. 22 (4), 415-423.

Kleen, M. (2000). "ToF-SIMS as a new analytical tool for studies of pulp fiber surface chemistry," International Symposium on Cellulose and Lignocellulosics Chemistry (ISCLC 2000), Kunming, China. 16-18, 290-294.

Kleen, M. (2005). "Surface lignin and extractives on hardwood RDH kraft pulp chemically characterized by ToF-SIMS," Holzforschung 59, 481-487.

DOI: $10.1515 /$ HF.2005.080

Kokkonen, P., Fardim, P., and Holmbom, B. (2004). "Surface distribution of extractives on TMP handsheets analyzed by ESCA, ATR-IR, ToF-SIMS and FE-SEM," Nord. Pulp Paper Res. J. 19, 318-324.

Koljonen, K., Oesterberg, M., Kleen, M., Fuhrmann, A., and Stenius, P. (2004). "Precipitation of lignin and extractives on kraft pulp: Effect on surface chemistry, surface morphology and paper strength," Cellulose 11, 209-224. DOI: 10.1023/B:CELL.0000025424.90845.c3

Magnusson, Y. (2008). "Identification and imaging of lipids in tissues using ToF-SIMS," Wallenberg Laboratory Department of Molecular and Clinical Medicine, Institution of Medicine, Sahlgrenska Academy, at Göteborg University, Göteborg, Sweden, 2008.

Mahajan, S., Jeremic, D., Goacher, R. E., and Master, E. R. (2012). "Mode of coniferous wood decay by the white-rot fungus Phanerochaete carnosa as elucidated by FTIR and ToF-SIMS," Appl. Microbiol. Biotechnol. 94 (5), 1303-1311.

DOI:10.1007/s00253-011-3830-1

Matsushita, Y., Suzuki, A., Sekiguchi, T., Saito, K., Imai, T., and Fukushima, K. (2008). "Mapping of the cationic starch adsorbed on pulp fibers by ToF-SIMS," Appl. Surf. Sci. 255, 1022-1024. DOI:10.1016/j.apsusc.2008.05.049

Mou, H. Y., Iamazaki, E., Zhan, H., Orblin, E., Fardim P. (2013a) "Advanced studies on the topochemistry of softwood fibres in low-consistency refining as analyzed by FE-SEM, XPS and ToF-SIMS”. BioResources, 8(2), 2325-2336.

Mou, H. Y., Li B., Heikkilä E., Iamazaki E., Zhan H., Fardim P. (2013b) "Low Consistency Refining of Eucalyptus Pulp: Effects on Surface Chemistry and Interaction with FWAs" BioResources, 8(4):5996-6013.

Mou, H. Y., Heikkilä, E., and Fardim, P. (2013c). "Topochemistry of alkaline, alkalineperoxide and hydrotropic pretreatments of common reed to enhance enzymatic hydrolysis efficiency," Bioresource Technol.150, 36-41.

DOI:10.1016/j.biortech.2013.09.093

Mou, H. Y., Orblin, E., Kruus, K., and Fardim, P. (2013d). "Topochemical pretreatment of wood biomass to enhance enzymatic hydrolysis of polysaccharides to sugars," Bioresource Technol. 142C, 540-545. DOI:10.1016/j.biortech.2013.05.046

Mou, H. Y., Heikkilä, E., and Fardim, P. (2014). "Topochemistry of environmentalfriendly pretreatments to enhance enzymatic hydrolysis of sugarcane bagasse to fermentable sugar," J. Agric. Food Chem. 23, 62(16), 3619-25.

DOI: $10.1021 /$ jf500582w

Orblin, E., and Fardim, P. (2010). "Surface chemistry of deinked pulps as analysed by XPS and ToF-SIMS," Surf. Interface Anal. 42, 1712-1722. DOI:10.1002/sia.3500 
Orblin, E., Valerie, E., and Fardim, P. (2011). "Surface chemistry of vessel elements by FE-SEM, XPS and ToF-SIMS," Holzforschung 65, 681-688.

DOI: $10.1515 / \mathrm{hf} .2011 .064$

Ozaki, Y., and Sawatari, A. (1998). "Surface characterization of a rosin sizing agent in paper by means of EPMA, ESCA and ToF-SIMS," Research Bulletin of the Government Printing Bureau, (04), 260-266.

Prairie, Application note 9811, Physical Eletronics, Inc., Eden Prairie, MN, USA, 1998.

Ragauskas, A. J., Williams, C. K., Davison, B. H., Britovsek, G., Cairney, J., Eckert, C.A., Frederick, W. J., Hallett, J. P., Leak, D. J., Liotta, C. L., Mielenz, J. R., Murphy, R., Templer, R., and Tschaplinski, T. (2006). "The path forward for biofuels and biomaterials," Science 311, 484-489. DOI: 10.1126/science.1114736

Rahikainen, J., Mikander, S., Marjamaa, K., Tamminen, T., Lappas, A., Viikari, L., and Kruus, K. (2011). "Inhibition of enzymatic hydrolysis by residual lignins from softwood - Study of enzyme binding and inactivation on lignin-rich surface," Biotechnol. Bioeng. 108, 2823-2834. DOI: 10.1002/bit.23242

Saito, K., Kato, T., Takamori, H., Kishimoto, T., and Fukushima, K. (2005). “A new analysis of the depolymerized fragments of lignin polymer using ToF-SIMS," Biomacromolecules 6, 2688-2696. DOI: 10.1021/bm050147o

Saito, K., Kato, T., Takamori, H., Kishimoto, T., Yamamoto, A., and Fukushima, K. (2006). "A new analysis of the depolymerized fragments of lignin polymer in the plant cell walls using ToF-SIMS," Appl. Surf. Sci. 252, 6734-6737.

DOI:10.1016/j.apsusc.2006.02.163

Saito, K., Kato, T., Tsuji, Y., and Fukushima, K. (2005). "Identifying the characteristic secondary ions of lignin polymer using ToF-SIMS," Biomacromolecules 6, 678-683. DOI:10.1021/bm049521v

Saito, K., Mitsutani, T., Imai, T., Matsushita, Y., Yamamoto, A., and Fukushima, K. (2008). "Chemical differences between sapwood and heartwood of Chamaecyparis obtuse detected by ToF-SIMS," Appl. Surf. Sci. 255, 1088-1091.

DOI:10.1016/j.apsusc.2008.05.145

Saito, K., Watanabe, Y., Shirakawa, M., Matsushita, Y., Imai, T., Koike T., Sano, Y., Funada, R., Fukazawa, K., and Fukushima, K. (2012). "Direct mapping of morphological distribution of syringyl and guaiacyl lignin in the xylem of maple by time-of-flight secondary ion mass spectrometry," The Plant J. 69, 542-552. DOI:10.1111/j.1365-313X.2011.04811.X

Saito, K., Watanabe, Y., Matsushita, Y., Imai, T., Koike, T., Sano, Y., Funada, R., Fukazawa, K., and Fukushima, K. (2014). "Aluminum localization in the cell walls of the mature xylem of maple tree detected by elemental imaging using time-of-flight secondary ion mass spectrometry (TOF-SIMS)," Holzforschung 68(1), 85. DOI:10.1515/hf-2012-0215

Tokareva, E. N. (2007). "Imaging of wood tissue by ToF-SIMS: Critical evaluation and development of sample preparation techniques," Appl. Surf. Sci. 253(75), 7569-7577. DOI:10.1016/j.apsusc.2007.03.059

Tokareva, E. N., Pranovich, A. V., and Holmbom, B. (2011). "Characteristic fragment ions from lignin and polysaccharides in ToF-SIMS," Wood Sci. Technol. 45, 767-785. DOI: $10.1007 / \mathrm{s} 00226-010-0392-9$

Tokareva1, E. N., Pranovich, A. V., Ek, P., and Holmbom, B. (2010). "Determination of anionic groups in wood by time-of-flight secondary ion mass spectrometry and laser 
ablation-inductively coupled plasma-mass spectrometry," Holzforschung 64, 35-43. DOI: $10.1515 / \mathrm{hf} .2010 .002$

Vega, B., Petzold-Welcke, K., Fardim, P., and Heinze, T. (2012). "Studies on the fibre surfaces modified with xylan polyelectrolytes," Carbohyd. Polym. 89,768-776. DOI:10.1016/j.carbpol.2012.04.006

Vega, B., Wondraczek, H., Zarth, C. S. P., Heikkila, E., Fardim, P., and Heinze, T. (2013). "Charge-directed fiber surface modification by molecular assemblies of functional polysaccharides," Langmuir 29, 13388-13395. DOI: 10.1021/la402116j

Wasser, R., and Brinen, J. S. (1998). "Effect of hydrolyzed ASA on sizing in calcium filled paper," Tappi J. 81(7), 139-144.

Zafeiropoulos, N. E., Vickers, P. E., Baillie, C. A., and Watts, J. F. (2003). “An experimental investigation of modified and unmodified flax fibres by means of XPS, ToF-SIMS and FTIR," J. Mater. Sci. 38(19), 3903-3914. DOI:10.1023/A:1026133826672

Zhou, C., Li, Q., Chiang, V. L., Lucia, L. A., and Griffis, D. P. (2011). "Chemical and spatial differentiation of syringyl and guaiacyl lignins in poplar wood via time-offlight secondary ion mass spectrometry," Anal.Chem. 83, 7020-7026. DOI:10.1021/ac200903y

Zimmerman, P. A., Hercules, D. M., Rulle, H., Zehnpfnning, J., and Benninghoven, A. (1995). "Direct analysis of coated and contaminated paper using time-of-flight secondary ion mass spectrometry," Tappi J. 78, 180-186.

Article submitted: December 17, 2015; Peer review completed: February 6, 2016; Revisions received March 8, 2016; Revisions accepted: March 15, 2016; Published: March 18, 2016.

DOI: 10.15376/biores.11.2.Mou 